\title{
Smartphone applications for sleep tracking: rating and perceptions about behavioral change among users
}

Reema A. Karasneh ${ }^{1}$

Sayer I. Al-Azzam ${ }^{2}$

Karem H. Alzoubi ${ }^{2,3 *}$

Sahar Hawamdeh ${ }^{2}$

Anan S. Jarab 2

Mohammad B. Nusair ${ }^{4}$

${ }^{1}$ Yarmouk University, Department of Basic Medical Sciences - Irbid - Jordan. ${ }^{2}$ Jordan University of Science and Technology, Department of Clinical Pharmacy - Irbid - Jordan.

${ }^{3}$ University of Sharjah, Department of Pharmacy Practice and Pharmcotherapeutics - Sharjah - UAE.

${ }^{4}$ Yarmouk University, Department of Pharmacy Practice - Irbid - Jordan.
*Corresponding author:

Karem H Alzoubi

E-mail: khalzoubi@just.edu.jo

Received: July 4, 2020;

Accepted: March 8, 2021.

\begin{abstract}
Introduction: This study aims to assess existing sleep apps for mobile phones to determine the perceived effect of these applications on user's attitudes, knowledge, willingness to change, and its likelihood to change behavior from a user's perspective. Material and Methods: A systematic search was conducted through Google play store and iTunes Apple store using terms related to sleep tracking. Apps were evaluated using Mobile Application Rating Scale (MARS) tool for assessing and classifying mobile health applications quality. Additionally, a convenience sample of subjects were asked to evaluate the included apps for perceived sleep behavior changes. Results: The average MARS app quality score on a 5-point scale was 3.3. Between $30-50 \%$ of participants believed that sleep tracker apps are likely to increase awareness about sleep patterns and sleep hygiene, influence sleep hygiene habits, and are likely to encourage help seeking for sleep hygiene when required. Conclusion: Apps available for sleep self-management and tracking may be valuable tools for selfmanagement of sleep disorder and/or improving sleep quality, yet they require improvement in terms of quality and content, highlighting the need for further validity studies.
\end{abstract}

Keywords: Sleep Tracker; Sleep Health; Smartphone Applications; Behavioural Change; Consumer Sleep Technology; Mobile Devices. 


\section{INTRODUCTION}

Sleep occupies between $20 \%$ and $40 \%$ of the human day. Even prehistoric evidence suggests the importance of sleep in human life, which is consistent with archaeological and historical accounts of sleep having a prominent and important role even in early human societies ${ }^{1,2}$. Therefore, sleep is considered a vital component of human life and essential for a person's health and well-being. It plays a critical role in different brain functions, such as facilitating memory consolidation, impacting cognitive and neurobehavioral performance, mood regulation, and subserving the brain clearance of various toxic waste products ${ }^{3-9}$.

According to the National Sleep Foundation, young adults aged between 18-25 years and adults aged 26 to 64 years should optimally have 7-9 hours of sleep. On the other hand, adults aged 65 years or older should sleep for 7-8 hours daily, not exceeding 9 hours and not getting less than 5 hours of sleep ${ }^{2}$. Sleep problems are widely prevalent, including deficiency in sleep quantity and quality and disturbance of sleep continuity, collectively referred to as sleep disruption. The characteristics of normal healthy sleep are a sufficient duration with regular and appropriate timing, and good quality in the absence of disorders and disturbances related to sleep ${ }^{2}$. On the long-term, sleep disturbances not only cause poor activity, fatigue, and decreased cognitive performance, but also increase the risk of early mortality, and several comorbid conditions such as cardiovascular disease, diabetes, hypertension, obesity, cancer, and depression ${ }^{10-18}$. Thus, getting enough sleep with good quality is important for human health and well-being.

Electronic health (eHealth) literacy is defined as "the ability of people to use emerging information and communications technologies to improve or enable health and health care" ${ }^{19}$. Mobile devices have become an inspirational and integral part of modern living, by being typically customized to the specific needs of individuals, creating deep personal relationships with their users ${ }^{20}$. Patients, as consumers, have a great need for mobile health (mHealth) applications that can help them with their medication adherence, as suggested by the $106 \%$ increase of iOS mHealth apps available to the public from 2013 to 2015. Interestingly, the mHealth apps grew from 43,689 in 2013 to 90,088 in $2015^{21}$.

Self-management applications on a smartphone have been advocated as a means to help people with sleep disturbance to achieve better levels of sleep control and better sleep quality outcomes. With increased mobile phone ownership on a global scale, a rapid development in mHealth technologies allows users to self-monitor and visualize their sleep patterns, symptoms, and behavioural data and aid them in taking appropriate actions on a potentially daily basis ${ }^{22}$. Most of the available sleep tracking apps are accelerometer-based and can employ built-in mobile sensors such as microphones and light detectors to obtain sleep data $^{1}$. However, and unlike accelerometry used in standard sleep assessment tools (e.g., actigraphy), mobile accelerometer operates via undefined and varying algorithms. Thus, their use remains a concern due to the lack of validation studies ${ }^{1,22}$.

These applications provide a wide range of functions, including smart alarms, sleep aids, sound recording during sleep, and analysis of sleep. Other applications were designed to assist healthcare professionals in monitoring and screening their patients for habitual snoring and obstructive sleep apnea ${ }^{23}$. A few health trackers were compared to standard sleep assessment tests including polysomnography (PSG), wrist actigraphy, and the Pittsburgh sleep quality index (PSQI) ${ }^{24}$. Parameters assessed in validation studies included sleep onset latency, total sleep time, snoring events, sleep stages, and sleep efficacy. Most applications have shown good correlation to wrist actigraphy but not PSG. Moreover, a drop in reliability was commonly seen in clinical populations compared to healthy users, a trend also seen with conventional actigraphy ${ }^{24-29}$.

Sleep health application may be valuable for user selfmanagement and improvement of sleep hygiene. In addition, they may help increase awareness and promote help seeking regarding sleep-related issues. However, the severe lack of validation studies raises concerns around their use and limits their function as alternatives to standard clinical tools. Moreover, assessment of available applications is necessary to guide physician recommendations of sleep tracker apps for patient use. To our knowledge, this is the first study to assess the perceived behavioural changes associated with sleep health applications.

\section{MATERIAL AND METHODS}

\section{Systematic search criteria}

Mobile apps for sleep tracking were identified by searching the Apple iTunes Store and Android Google Play store using mobile devices. Sleep trackers were defined as applications that measure sleep data such as sleep duration and/or quality ${ }^{30}$. The following search terms were used: "sleep tracker", "sleep analysis", and "sleep cycle", as they are the most commonly used description of these term. Each term was separately searched at both app stores during November 2019. Apps retrieved using the above-mentioned search terms were downloaded onto their respective devices (iPhone or Android) and then duplicates were removed. Search was done out of Jordan. Apps were included if they were available in both stores in English language, have a stand-alone functionality (i.e., not part of another app), and were free to download. Apps were excluded if their core function was sleep aid that include features such as calming visual graphics, relaxing music, nature sounds, and/or white noise $e^{31}$, meditation apps; if they were used for babies, if they need to be connected with another device or sensor to conduct their core function, or if they were paid apps. Apps that were found not to be a sleep-tracking app were also excluded (Figure 1).

\section{Data extraction}

A detailed review of the included apps was conducted, and data was independently extracted by two reviewers. The data included information on classification, and objective and subjective qualities, as described in the mobile application rating scale (MARS). Classification of data included characteristics of apps such as descriptive information on rating and technical aspects such as password protection, confidentiality, and security. Objective quality included engagement, functionality, 


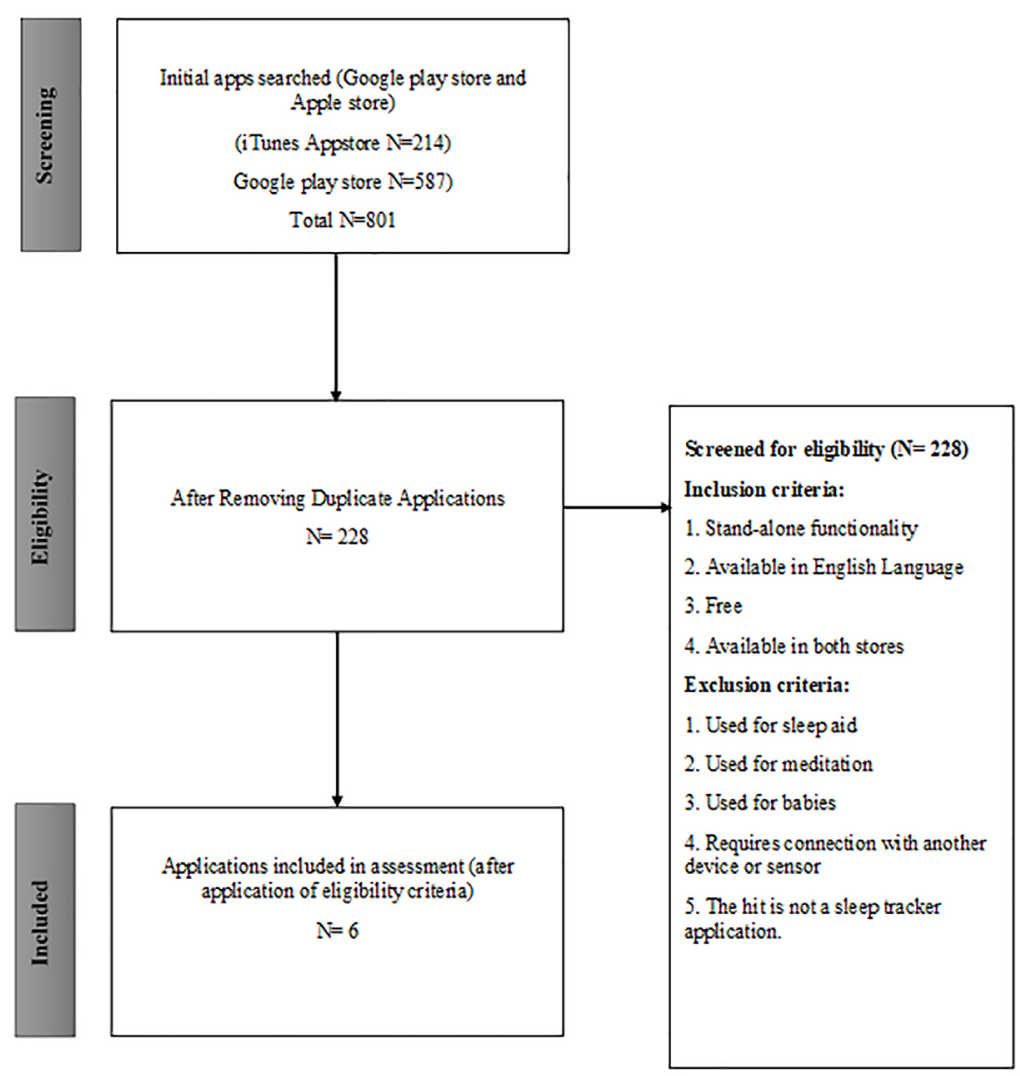

Figure 1. Schematic presentation of search responses processing.

aesthetics, and information features. Presence or absence of objective quality features was assessed in extracted information and if not found then was considered absent ${ }^{32,33}$.

\section{Assessment of sleep tracker mobile apps}

The MARS tool was used for assessing the quality of health mobile apps for sleep tracking. The tool included three main sections; app description, application objective section, which is divided into 4 scales assessing application engagement, functionality, aesthetics, and quality of information, and subjective application quality, which evaluated overall user satisfaction. A 5-point Likert scale was used for MARS items scoring. The final MARS score included average quality score and subjectivity scores.

\section{Perception about behavioural change assessment}

We assessed users' perceptions about the behavioural changes associated with the retrieved apps using an app-specific behavioural change MARS subscale ${ }^{34}$. The tool was developed on a web-based platform to facilitate completion and collection of data (Supplementary file I). The protocol of this study was approved by the institutional review board of Jordan University of Science and Technology, Jordan, and written informed consent form were obtained from study participants. For each app, five independent reviews from participants from the community were considered. Therefore, invitations were sent via email using conveniencesampling technique (i.e., depending on accessible e-mail lists to the research team, which included more than 1,000 e-mails).
Participants in the study were asked to download and use one of the sleep tracker apps for two weeks and to fill-out the questionnaire that consisted of five questions related to behaviour change. Content related to the behaviors was reviewed and scored for each app to assess potential impact on user sleep hygiene awareness of the importance of addressing sleep patterns, knowledge or understanding, attitudes toward improving, intentions or motivations to change or address, help-seeking, and behavior change. Each of these questions had five-points, from one to five; where one represented strongly disagree and five represented strongly agree and average score was calculated for each app. Sleep hygiene was defined as by the criteria set by the National Sleep Foundation, USA (https:/ / www.sleepfoundation.org/articles/sleep-hygiene).

\section{RESULTS}

\section{Evaluation of sleep tracker apps}

Six sleep tracker applications have met inclusion/exclusion criteria and, thus, were included in the study. The two reviewers have evaluated the included apps for quality and subjectivity. Table 1 shows the average score between the two reviewers. Circadia track received the highest ranking for quality (3.6), followed by Sleeptic:Sleep Track \& Smart AlarmClock (3.5), and Sleep CENTRAL (3.3). Circadia Track also had the highest subjectivity score (3.25), followed by Sleeptic:Sleep Track \& Smart AlarmClock (2.88), and Zen Sleep Cycle Alarm Clock (2.75). The overall mean scores for quality and subjectivity were 3.3 and 2.66, respectively (Table 1). Table 2 shows mobile applications' functionalities and description of apps objective quality, functionality, aesthetics, and information features are shown in Table 3. 
Smartphone applications for sleep tracking

Table 1. Mobile application rating scale scores.

\begin{tabular}{|c|c|c|c|c|c|}
\hline App name & Quality reviewer 1 & Quality reviewer 2 & Average quality & Subjective reviewer 1 & Subjective reviewer 2 \\
\hline Airweave sleep analysis & 2.975 & 3.31 & 3.1425 & 2 & 2.5 \\
\hline Circadia Track & 3.3525 & 3.78 & 3.56625 & 2.75 & 3.75 \\
\hline JUKUSUI & 2.6625 & 3.49 & 3.07625 & 2 & 2.5 \\
\hline Sleep CENTRAL & 3.2575 & 3.4 & 3.32875 & 2.75 & 2.5 \\
\hline Sleeptic:Sleep Track \& Smart AlarmClock & 3.475 & 3.6 & 3.5375 & 3 & 2.75 \\
\hline Zen Sleep Cycle Alarm Clock & 3.34 & 3.2 & 3.27 & 3 & 2.5 \\
\hline
\end{tabular}

Table 2. Mobile applications' functionalities.

\begin{tabular}{l|c}
\hline App Name & Functionalities \\
\hline Airweave sleep analysis & $\begin{array}{c}\text { Sleep cycle measurement and graphing, } \\
\text { smart alarm. }\end{array}$ \\
Circadia Track & $\begin{array}{c}\text { Sleep diary, sleep metrics and sleep stages } \\
\text { analysis, contactless sleep tracking. } \\
\text { Snoring logs, sleep log, music, smart alarm. } \\
\text { Jukusui }\end{array}$ \\
$\begin{array}{l}\text { Sleep, HR, RR*, and body movement } \\
\text { Sleep Central }\end{array}$ & $\begin{array}{c}\text { recording, music, smart alarm. } \\
\text { Sleeptic:Sleep Track \& Smart }\end{array}$ \\
AlarmClock & scoring, Google Fit integration. \\
Zen Sleep Cycle Alarm Clock & Smart alarm, sleep staging, dream log. \\
\hline
\end{tabular}

Assessment of perceptions about sleep behavioral change among users:

Table 4 shows characteristics of participants $(n=30)$. Slightly under half of participants $(46.7 \%, \mathrm{n}=14)$ had prior experience with mobile health apps. Most were non-smokers $(90 \%, \mathrm{n}=27)$. Around $36.7 \%(n=11)$ did not exercise at all, while slightly over half $(56.7 \%)$ exercised once to thrice a week. The majority of respondents were medically free $(80 \%, \mathrm{n}=24)$ and did not have any sleep disorders $(73.3 \%, \mathrm{n}=22)$, while only $10 \%(\mathrm{n}=3)$ reported having insomnia and $16.7 \%(n=5)$ had bruxism. Sleep routine was also assessed for respondents (Table 5). Half of the study population did not have a bed or room partner, while the other half had one. The majority of participants $(46.7 \%, n=14)$ reported going to bed between $10-12$ p.m. During weekdays, most people $(60 \%, n=18$, ) had to wake up before 9:00 a.m., while at weekends, only 53.3\% woke-up before 9:00 a.m. Participant also achieved more actual sleep hours during weekends compared to weekdays. Subjects were asked to rate their sleep quality from "poor" to "very good". Over half of participants $(56.7 \%, \mathrm{n}=17)$ rated their sleep quality as 'good'.
Figure 2 shows the common reasons for using sleep apps among participants. Most participants reported using sleep trackers apps to track and gain understanding of their sleep $(46.7 \%, n=14)$. Meanwhile, 33\% $(n=10)$ used such apps to wake up at the desirable time. Other targets for sleep apps use included improving sleep at night $(13.3 \%, \mathrm{n}=4)$, getting adequate sleep $(16.7 \%, \mathrm{n}=5)$, and gaining knowledge about the best sleep time $(16.7 \%, n=5)$ and duration $(23.3 \%, n=7)$.

After downloading and using sleep tracker apps included in the study, participants completed an app evaluation form based on the MARS tool (Table 6 ). About $36.6 \%$ of participants believed that sleep tracker apps are likely to increase awareness of the importance of addressing sleep patterns. A similar percent $(33.3 \%)$ agreed that such apps are likely to increase knowledge/understanding of sleep hygiene. Most agreed that apps can affect the intent to change sleep hygiene habits $(40 \%$, $\mathrm{n}=12$ ). Slightly below half agreed that sleep tracker apps are likely to encourage further help seeking for sleep hygiene when required. Finally, 33\% of respondents agreed that sleep apps are likely to increase or decrease sleep hygiene. However, 40.0$53.3 \%$ of subjects of the study chose the option "neutral" for items of the MARS tool subscale. Table 7 shows app specific behavioral impact score. "Sleeptic: Sleep Track \& Smart Alarm Clock" app had the highest app specific score based on the rating of five independent reviewers. However, "JUKUSUI" had the lowest app score.

\section{DISCUSSION}

Over the past decade, mobile technology and smartphones have become an inspirational and integral part of modern living. Being widely used in the healthcare sector,

Table 3. Description of app quality rating (assessed by four domains of MARS).

\begin{tabular}{|c|c|c|c|c|c|c|c|c|c|c|c|c|}
\hline App name & 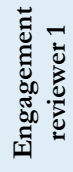 & 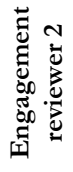 & $\begin{array}{c}\text { Mean } \\
\text { engagement }\end{array}$ & 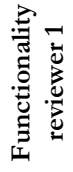 & 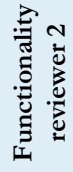 & $\begin{array}{c}\text { Mean } \\
\text { functionality }\end{array}$ & 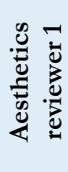 & 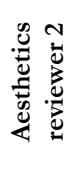 & $\begin{array}{c}\text { Mean } \\
\text { aesthetics }\end{array}$ & 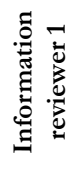 & 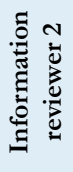 & $\begin{array}{c}\text { Mean } \\
\text { information }\end{array}$ \\
\hline Airweave sleep analysis & 3 & 3 & 3 & 3 & 4.25 & 3.625 & 3.3 & 3 & 3.15 & 2.6 & 3 & 2.8 \\
\hline Circadia Track & 3.2 & 3.8 & 3.5 & 3.75 & 3.75 & 3.75 & 3.3 & 4 & 3.65 & 3.16 & 3.6 & 3.38 \\
\hline JUKUSUI & 2.6 & 3.8 & 3.2 & 2.75 & 3.75 & 3.25 & 3 & 3.66 & 3.33 & 2.3 & 2.75 & 2.525 \\
\hline Sleep CENTRAL & 3.2 & 3.6 & 3.4 & 4 & 3.75 & 3.875 & 3 & 3.33 & 3.315 & 2.83 & 3 & 2.915 \\
\hline $\begin{array}{l}\text { Sleeptic:Sleep Track \& } \\
\text { Smart AlarmClock }\end{array}$ & 3.6 & 3.8 & 3.7 & 4 & 4 & 4 & 4 & 4 & 4 & 2.3 & 2.66 & 2.48 \\
\hline $\begin{array}{l}\text { Zen Sleep Cycle Alarm } \\
\text { Clock }\end{array}$ & 3.4 & 2.8 & 3.1 & 4 & 4 & 4 & 3.3 & 3.33 & 3.315 & 2.66 & 3 & 2.83 \\
\hline
\end{tabular}


Table 4. Characteristics of study participants.

\begin{tabular}{lc}
\hline Characteristics & n (\%) \\
\hline Gender & \\
Male & $4(13.3)$ \\
Female & $26(86.7)$ \\
Marital status & \\
Single & $25(83.3)$ \\
Married & $5(16.7)$ \\
Highest education & \\
High school & $2(6.7)$ \\
College student & $28(93.3)$ \\
Occupation & \\
Unemployed/housewife & $5(16.7)$ \\
Employed & $6(20)$ \\
Other & $19(63.3)$ \\
Platform & \\
Phone with Android operation system & $18(60)$ \\
iPhone & $12(40)$ \\
Experience with mHealth app & \\
Yes & $14(46.7)$ \\
No & $16(53.3)$ \\
Smoking & \\
Yes & $3(10)$ \\
No & $27(90)$ \\
Exercise/week & $11(36.7)$ \\
Once/week & $9(30)$ \\
2 times or more/week & $10(33.3)$ \\
\hline & \\
\hline
\end{tabular}

mobile health and mHealth applications have started to establish their place and take part in healthcare ${ }^{35,36}$. In this study, we present a systematic evaluation of sleep tracker apps using the MARS tool. In addition, a MARS sub-scale tool was used for assessment of user perceptions about app-related behavioral changes in a sample of adults.

On a 5-point rating scale, the highest score achieved for quality was 3.6, compared to 3.25 in subjectivity, both achieved by the app "Circadia Track". Meanwhile, the average MARS score for app quality among all applications was 3.3. This was similar to results from Choi et al. $(2018)^{22}$, where the median overall MARS score reached 3.1. Choi et al. (2018) 22 screened and evaluated 73 sleep health applications using the MARS tool and found that over half of the applications achieved a minimum acceptability score of 3.0. In general, such a mean of about 3 out of a 5 point on MARS scale indicate the need for more work to improve the validity, and benefits of these apps to users. Yet, apps included in this study offered multiple features such as tracking sleep stages, stage-specific alarms, heart rate and respiratory rate monitors, body movement monitors, and graph displays. Some of the apps, such as Sleep CENTRAL, also provided education on sleep hygiene improvement. In addition, the app Circadia Track offers analysis of sleep stages, circadian rhythm, and sleep metrics (e.g., sleep onset, time, and efficiency). Such differences in features could be suggested reasons for differences in results/scores among apps. It should also be considered that paid applications, which were excluded
Table 5. Sleep routine and habits of study participants.

\begin{tabular}{|c|c|}
\hline Characteristics & $\mathrm{n}(\%)$ \\
\hline \multicolumn{2}{|l|}{ Snoring } \\
\hline Yes & $3(10)$ \\
\hline No & $18(60)$ \\
\hline I don't know & $9(30)$ \\
\hline \multicolumn{2}{|c|}{ Bed partner or roommate } \\
\hline Yes & $15(50.0)$ \\
\hline No & $15(50.0)$ \\
\hline \multicolumn{2}{|l|}{ Bedtime } \\
\hline Earlier than 10:00 p.m. & $7(23.4)$ \\
\hline 10:00 p.m. - 12:00 a.m. & $14(46.7)$ \\
\hline Later than 12:00 a.m. & $9(30.0)$ \\
\hline \multicolumn{2}{|l|}{ Time to fall asleep } \\
\hline Less than 15 minutes & $12(40.0)$ \\
\hline 15-29 minutes & $6(20.0)$ \\
\hline 30 minutes or more & $12(40.0)$ \\
\hline \multicolumn{2}{|c|}{ Wake up time during weekdays } \\
\hline Earlier than 9:00 a.m. & $27(90.0)$ \\
\hline 9:00 a.m. or later & $3(10.0)$ \\
\hline \multicolumn{2}{|c|}{ Average sleep duration at weekdays } \\
\hline Less than 8 hours & $20(66.7)$ \\
\hline 8 hours or more & $10(33.3)$ \\
\hline \multicolumn{2}{|c|}{ Sleep duration on weekends } \\
\hline Less than 8 hours & $12(55.7)$ \\
\hline 8 hours or more & $18(45.3)$ \\
\hline \multicolumn{2}{|c|}{ Wake up time on weekends } \\
\hline Earlier than 9:00 a.m. & $16(53.3)$ \\
\hline 9:00 a.m. and later & $14(46.7)$ \\
\hline \multicolumn{2}{|c|}{ Self-rating of sleep quality } \\
\hline Very good & $4(13.3)$ \\
\hline Good & $17(56.7)$ \\
\hline Average & $8(26.7)$ \\
\hline Poor & $1(3.3)$ \\
\hline \multicolumn{2}{|c|}{ Typical sleeping position } \\
\hline Back sleeping & $3(10)$ \\
\hline Side sleeping & $26(86.7)$ \\
\hline Stomach & $1(3.3)$ \\
\hline Head elevated & $0(0)$ \\
\hline
\end{tabular}

from this study, could offer additional functions, and have higher ratings.

To validate the algorithms used in calculating sleep parameters, multiple mobile applications for sleep tracking and management were tested in clinical studies ${ }^{22}$. Those apps were compared to standard sleep tests such as PSG, wrist actigraphy, and the Pittsburgh sleep quality index for validity and reliability in assessing sleep ${ }^{24}$. Parameters commonly assessed included total sleep time, sleep stages (wake, light sleep, deep sleep, rapid eye movement (REM), sleep latency, snoring events, sleep duration, and sleep efficiency). Correlation between the assessed apps and PSG varied according to study population (healthy vs. clinical) and the sleep parameter assessed. Good correlation with 


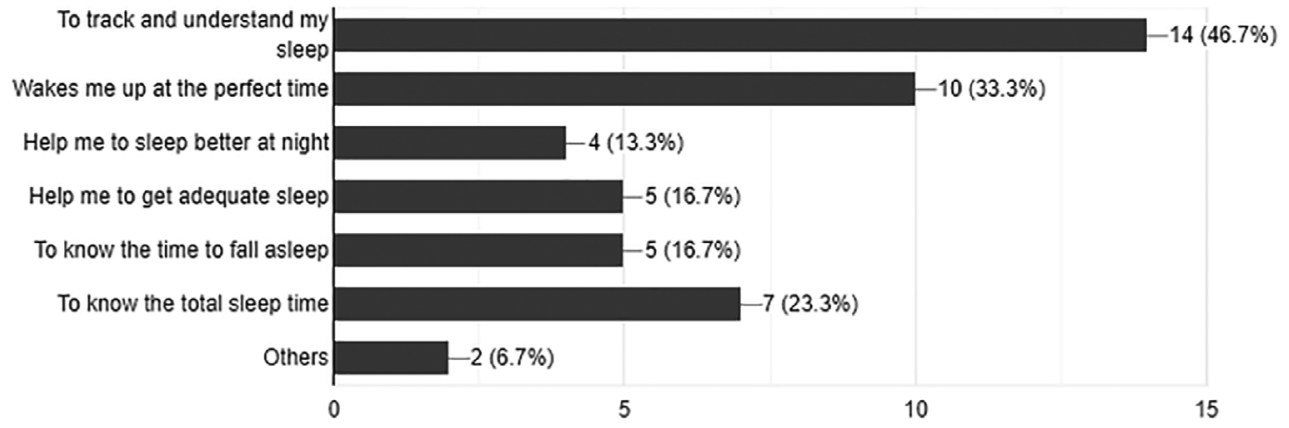

Figure 2. Reasons for using sleep tracker mobile applications.

Table 6. Participant perceptions to the behavioural changes subscale as adapted from MARS tool.

\begin{tabular}{|c|c|}
\hline Item & $\mathrm{n}(\%)$ \\
\hline \multicolumn{2}{|c|}{$\begin{array}{l}\text { Awareness: this app is likely to increase awareness of the } \\
\text { importance of addressing sleep patterns. }\end{array}$} \\
\hline 1 (Strongly disagree) & $2(6.7)$ \\
\hline 2 (Disagree) & $5(16.7)$ \\
\hline 3 (Neutral) & $12(40)$ \\
\hline 4 (Agree) & $10(33.3)$ \\
\hline 5 (Strongly agree) & $1(3.3)$ \\
\hline \multicolumn{2}{|c|}{$\begin{array}{l}\text { Knowledge: this app is likely to increase knowledge/ } \\
\text { understanding of sleep hygiene. }\end{array}$} \\
\hline 1 (Strongly disagree) & $2(6.7)$ \\
\hline 2 (Disagree) & $2(6.7)$ \\
\hline 3 (Neutral) & $16(53.3)$ \\
\hline 4 (Agree) & $9(30)$ \\
\hline 5 (Strongly agree) & $1(3.3)$ \\
\hline \multicolumn{2}{|c|}{$\begin{array}{l}\text { Attitudes: This app is likely to change attitudes toward } \\
\text { improving sleep hygiene. }\end{array}$} \\
\hline 1 (Strongly disagree) & $2(6.7)$ \\
\hline 2 (Disagree) & $4(13.3)$ \\
\hline 3 (Neutral) & $13(43.3)$ \\
\hline 4 (Agree) & $11(36.7)$ \\
\hline 5 (Strongly agree) & $0(0)$ \\
\hline \multicolumn{2}{|c|}{$\begin{array}{l}\text { Intention to change: this app is likely to increase intentions/ } \\
\text { motivation to address sleep hygiene. }\end{array}$} \\
\hline 1 (Strongly disagree) & $2(6.7)$ \\
\hline 2 (Disagree) & $2(6.7)$ \\
\hline 3 (Neutral) & $14(46.7)$ \\
\hline 4 (Agree) & $12(40)$ \\
\hline 5 (Strongly agree) & $0(0)$ \\
\hline \multicolumn{2}{|c|}{$\begin{array}{l}\text { Help seeking: use of this app is likely to encourage further help } \\
\text { seeking for sleep hygiene (if it is required). }\end{array}$} \\
\hline 1 (Strongly disagree) & $2(6.7)$ \\
\hline 2 (Disagree) & $2(6.7)$ \\
\hline 3 (Neutral) & $14(46.7)$ \\
\hline 4 (Agree) & $12(40)$ \\
\hline 5 (Strongly agree) & $0(0)$ \\
\hline \multicolumn{2}{|c|}{$\begin{array}{l}\text { Perception about behaviour change: use of this app is likely } \\
\text { to increase/decrease sleep hygiene. }\end{array}$} \\
\hline 1 (Strongly disagree) & $2(6.7)$ \\
\hline 2 (Disagree) & $3(10)$ \\
\hline 3 (Neutral) & $15(50)$ \\
\hline 4 (Agree) & $10(33.3)$ \\
\hline 5 (Strongly agree) & $0(0)$ \\
\hline
\end{tabular}

PSG was seen among parameter-based apps in detecting sleep stages, while accelerometer-based apps showed poor correlation with PSG sleep substages. For example, Bhat et al. (2015) ${ }^{27}$ assessed the accelerometer-based app "Sleep Time" in a sample of 20 healthy subject, who also underwent a full night sleep study using PSG. Despite having high sensitivity for detecting sleep and wake (89.9\%), the app was not correlated with PSG sleep parameters. Meanwhile, results from the app "Sleep on Cue" were found to be significantly correlated to those of PSG regarding sleep onset latency (SOL) ${ }^{37}$. When compared to wrist actigraphy, sleep apps generally displayed accurate results in healthy populations. Meanwhile, a drop in accuracy is seen with both actigraphy and sleep trackers when assessing sleepwake in clinical populations ${ }^{24}$. This was confirmed in a study where a noticeable decrease in reliability of measuring sleep parameters (e.g., total sleep time, waking after sleep onset, and sleep efficiency) was seen among patients with poorer sleep ${ }^{1}$.

Due to limitations in accuracy and reliability, sleep health applications may not be recommended in clinical population or as diagnostic tools ${ }^{24-29,38}$. Among participants of the current study, sleep apps were used for keeping track of sleep and increasing knowledge about the recommended sleep time and duration. About 13\% also aimed to improve nighttime sleep using such apps. Therefore, they may prove useful as self-management methods for improving sleep hygiene and engaging patients in their therapy process. In fact, several studies have shown self-help and patient-centered interventions to be efficacious in improving sleep and sleep-related disorders ${ }^{39,1}$. For example, self-help cognitive behavioural therapy (CBT) has shown efficacy as a treatment for insomnia, and might be a useful alternative when face-to-face CBT is not possible ${ }^{39}$. In addition, sleep hygiene education has been proposed as a method for sleep management and improvement ${ }^{40}$.

Sleep hygiene $(\mathrm{SH})$ refers to a set of practices and factors recommended for improving sleep that include exercise, stress management, limiting bedtime caffeine intake, establishing a consistent sleep routine, limiting daytime napping, among many others $^{41}$. In two studies among university students in Kuwait and Hong Kong, sleep hygiene practice was shown to be associated with sleep quality ${ }^{42,43}$. Moreover, $\mathrm{SH}$ education is commonly indicated for managing sleep disorders, such as insomnia, with comparable or slightly lower efficacy than cognitive behavioural therapy ${ }^{40}$. In this study, we evaluated the behavioural changes 
Table 7. App specific behavioural impact score.

\begin{tabular}{|c|c|c|c|c|c|c|c|}
\hline & Strongly disagree & Disagree & Neutral & Agree & Strongly agree & Mean score & App score \\
\hline \multicolumn{8}{|c|}{ Sleeptic: Sleep Track \& Smart AlarmClock } \\
\hline Awareness & 0 & 0 & 2 & 2 & 1 & 3.8 & 3.50 \\
\hline Knowledge & 0 & 0 & 2 & 2 & 1 & 3.8 & \\
\hline Attitudes & 0 & 0 & 2 & 3 & 0 & 3.6 & \\
\hline Intention to change & 0 & 0 & 3 & 2 & 0 & 3.4 & \\
\hline Help seeking & 0 & 0 & 4 & 1 & 0 & 3.2 & \\
\hline Behaviour change & 0 & 0 & 4 & 1 & 0 & 3.2 & \\
\hline \multicolumn{8}{|c|}{ Airweave sleep analysis } \\
\hline Awareness & 0 & 1 & 2 & 2 & 0 & 3.2 & 3.13 \\
\hline Knowledge & 0 & 1 & 2 & 2 & 0 & 3.2 & \\
\hline Attitudes & 0 & 1 & 3 & 1 & 0 & 3 & \\
\hline Intention to change & 0 & 1 & 1 & 3 & 0 & 3.4 & \\
\hline Help seeking & 0 & 1 & 3 & 1 & 0 & 3 & \\
\hline Behaviour change & 0 & 1 & 3 & 1 & 0 & 3 & \\
\hline \multicolumn{8}{|l|}{ Jukusui } \\
\hline Awareness & 0 & 2 & 2 & 1 & 0 & 2.8 & 2.47 \\
\hline Knowledge & 0 & 0 & 4 & 1 & 0 & 3.2 & \\
\hline Attitudes & 2 & 1 & 1 & 1 & 0 & 2.2 & \\
\hline Intention to change & 2 & 1 & 1 & 1 & 0 & 2.2 & \\
\hline Help seeking & 2 & 1 & 1 & 1 & 0 & 2.2 & \\
\hline Behaviour change & 2 & 1 & 1 & 1 & 0 & 2.2 & \\
\hline \multicolumn{8}{|l|}{ Circadia Track } \\
\hline Awareness & 2 & 1 & 1 & 1 & 0 & 2.2 & 3.27 \\
\hline Knowledge & 2 & 0 & 1 & 2 & 0 & 2.6 & \\
\hline Attitudes & 0 & 0 & 2 & 3 & 0 & 3.6 & \\
\hline Intention to change & 0 & 0 & 2 & 3 & 0 & 3.6 & \\
\hline Help seeking & 0 & 0 & 1 & 4 & 0 & 3.8 & \\
\hline Behaviour change & 0 & 0 & 1 & 4 & 0 & 3.8 & \\
\hline \multicolumn{8}{|l|}{ Sleep Central } \\
\hline Awareness & 0 & 0 & 2 & 3 & 0 & 3.6 & 3.33 \\
\hline Knowledge & 0 & 0 & 4 & 1 & 0 & 3.2 & \\
\hline Attitudes & 0 & 2 & 2 & 1 & 0 & 2.8 & \\
\hline Intention to change & 0 & 0 & 3 & 2 & 0 & 3.4 & \\
\hline Help seeking & 0 & 0 & 1 & 4 & 0 & 3.8 & \\
\hline Behaviour change & 0 & 1 & 2 & 2 & 0 & 3.2 & \\
\hline \multicolumn{8}{|c|}{ Zen Sleep Cycle Alarm Clock } \\
\hline Awareness & 0 & 1 & 3 & 1 & 0 & 3 & 3.16 \\
\hline Knowledge & 0 & 1 & 3 & 1 & 0 & 3 & \\
\hline Attitudes & 0 & 0 & 3 & 2 & 0 & 3.4 & \\
\hline Intention to change & 0 & 0 & 4 & 1 & 0 & 3.2 & \\
\hline Help seeking & 0 & 0 & 4 & 1 & 0 & 3.2 & \\
\hline Behaviour change & 0 & 0 & 4 & 1 & 0 & 3.2 & \\
\hline
\end{tabular}

associated with five sleep tracker apps as perceived by healthy adult participants. After using the apps, participants shared their assessment of app-related behavioural change aspects. Those included awareness, knowledge, attitudes, intention to change, help seeking, and perceived change of behaviour. Most participants believed the apps were helpful in increasing awareness and knowledge about sleep hygiene. Furthermore, they believed sleep trackers would lead to taking action in addressing sleep problems, including seeking help from professionals. Overall, participants agreed that the use of sleep trackers could affect sleep hygiene, either positively or negatively. Although data are limited about app-related behavioural change, a previous study found the app "Sleep Cycle" to be helpful in increasing awareness of sleep problems in children ${ }^{44}$. In our study, "Sleeptic: Sleep Track \& Smart Alarm Clock" app was the most helpful app to increase awareness of the importance of addressing sleep patterns.

To our knowledge, this study is the first to assess perceptions about behavioural changes associated with sleep trackers from user's perspective. This might prove helpful in highlighting the role of such apps in patient-centred selfmanagement and sleep hygiene education. Additionally, an evaluation of sleep trackers apps available for mobile use was presented, with the aim of aiding physicians in choosing the most suitable app for patients. Current assessment was limited to applications available in English and requiring no subscription fees. Apps available on platforms other than Google Play Store or Apple App Store were also not included. Notably, in this study, 
we did not directly measure change in sleep hygiene. We rather assessed the perception of study participants about the effect of the use of the apps on user's attitudes, knowledge, willingness to change, as well as its likelihood to change user's behaviour. The term sleep hygiene was explained to the study participants as per its set criteria of practices ${ }^{45}$. Directly measuring the actual change in sleep hygiene, how those apps impact a person already has a good quality of sleep, or those who use the apps, but skip for some days will be the matter of our future work. Moreover, a comprehensive study that include measuring apps induced behavioural change among separate groups of ages, genders, patients with some typical diseases is warranted.

We believe that sleep apps may increase sleep quality by improving awareness about self-management, help seeking regarding sleep-related issues, and/or improvement of sleep hygiene. Another point of concern would be if any improvement in the sleep quality during the use of the apps is actually because of those apps themselves or because of patients' thoughts about their sleep. To verify this, a separate comprehensive study is needed. Another possible limitation of this study is the use of e-mail lists to recruit subjects, which produced a relatively low response rate with majority of subjects being females. Thus, once again, a more comprehensive study is needed.

\section{CONCLUSION}

Amid concerns regarding the limited validity of mobile sleep trackers and variation in results compared to golden standard PSG, other roles of such apps must be considered. We conclude that sleep trackers may be useful in improving user's self-management, and increasing sleep hygiene awareness, knowledge, and behaviours. Thus, apps may present valuable tools for improving sleep quality. However, continuous audits and validation trials for available apps are vital to improve their quality. It is recommended to assess behavioral changes associated with sleep trackers in different populations, such as elders, and people with sleep disorders and major illnesses.

\section{REFERENCES}

1. Fietze I. Sleep applications to assess sleep quality. Sleep Med Clin. 2016 Dec;11(4):461-8. DOI: https://doi.org/10.1016/j.jsmc.2016.08.008

2. Grandner MA. Sleep, health, and society. Sleep Med Clin. 2017 Mar;12(1):1-22. DOI: https://doi.org/10.1016/j.jsmc.2016.10.012

3. Yoo SS, Hu PT, Gujar N, Jolesz FA, Walker MP. A deficit in the ability to form new human memories without sleep. Nat Neurosci. 2007 Feb;10:385-92. DOI: https://doi.org/10.1038/nn1851

4. Rasch B, Born J. About sleep's role in memory. Physiol Rev. 2013 Apr;93(2):681-766. DOI: https://doi.org/10.1152/physrev.00032.2012

5. Lim J, Dinges DF. A meta-analysis of the impact of short-term sleep deprivation on cognitive variables. Psychol Bull. 2010;136(3):375-89. DOI: https://doi.org/10.1037/a0018883

6. Van Dongen HPA, Maislin G, Mullington JM, Dinges DF. The cumulative cost of additional wakefulness: dose-response effects on neurobehavioral functions and sleep physiology from chronic sleep restriction and total sleep deprivation. Sleep. 2003 Mar;26(2):117-26. DOI: https://doi.org/10.1093/sleep/26.2.117

7. Minkel JD, Banks S, Hataik OO, Moreta MC, Jones CW, McGlinchey EL, et al. Sleep deprivation and stressors: evidence from elevated negative affect in response to mild stressors when sleep deprived. Emotion. 2012 Oct;12(5):1015-20.

8. Mendelsohn AR, Larrick JW. Sleep facilitates clearance of metabolites from the brain: glymphatic function in aging and neurodegenerative diseases. Rejuvenation Res. 2013 Dec;16(6):518-23. DOI: https://doi. org/10.1089/rej.2013.1530
9. Xie L, Kang H, Xu Q, Chen MJ, Liao Y, Thiyagarajan M, et al. Sleep drives metabolite clearance from the adult brain. Science. 2013 Oct;342(6156):373-7. DOI: https://doi.org/10.1126/science.1241224

10. Kawakami N, Takatsuka N, Shimizu H. Sleep disturbance and onset of type 2 diabetes. Diabetes Care. 2004 Jan;27(1):282-3. DOI: https://doi. org/10.2337/diacare.27.1.282

11. Xie D, Li W, Wang Y, Gu H, Teo K, Liu L, et al. Sleep duration, snoring habits and risk of acute myocardial infarction in China population: results of the INTERHEART study. BMC Public Health. 2014 May;14:531. DOI: https://doi.org/10.1186/1471-2458-14-531

12. Choi JW, Song JS, Lee YJ, Won T Bin, Jeong DU. Increased mortality in relation to insomnia and obstructive sleep apnea in Korean patients studied with nocturnal polysomnography. J Clin Sleep Med. 2017 Jan;13(1):49-56. DOI: https://doi.org/10.5664/jcsm.6386

13. Watson NF, Badr MS, Belenky G, Bliwise DL, Buxton OM, Buysse D, et al. Joint consensus statement of the American Academy of Sleep Medicine and Sleep Research Society on the recommended amount of sleep for a healthy adult: methodology and discussion. J Clin Sleep Med. 2015;11(8):931-52. DOI: https://doi.org/10.5664/jcsm.4950

14. Vgontzas AN, Liao D, Bixler EO, Chrousos GP, Vela-Bueno A. Insomnia with objective short sleep duration is associated with a high risk for hypertension. Sleep. 2009 Apr;32(4):491-7. DOI: https://doi. org/10.1093/sleep/32.4.491

15. Sun W, Huang Y, Wang Z, Yu Y, Lau A, Ali G, et al. Sleep duration associated with body mass index among Chinese adults. Sleep Med. 2015 May;16(5):612-6. DOI: https://doi.org/10.1016/j.sleep.2014.12.011

16. Kakizaki M, Kuriyama S, Sone T, Ohmori-Matsuda K, Hozawa A, Nakaya N, et al. Sleep duration and the risk of breast cancer: the Ohsaki cohort study. Br J Cancer. 2008 Sep;99:1502-5. DOI: https://doi.org/10.1038/sj.bjc.6604684

17. Jiao L, Duan Z, Sangi-Haghpeykar H, Hale L, White DL, El-Serag HB. Sleep duration and incidence of colorectal cancer in postmenopausal women. Br J Cancer. 2013 Jan;108:213-21. DOI: https://doi.org/10.1038/bjc.2012.561

18. Stickley A, Leinsalu M, DeVylder JE, Inoue Y, Koyanagi A. Sleep problems and depression among 237023 community-dwelling adults in 46 low- and middle-income countries. Sci Rep. 2019 Aug;9:12011. DOI: https://doi.org/10.1038/s41598-019-48334-7

19. Neter E, Brainin E. eHealth literacy: extending the digital divide to the realm of health information. J Med Internet Res. 2012 Jan/Feb;14(1):e19. DOI: https://doi.org/10.2196/jmir.1619

20. World Health Organization (WHO). Global difusion of eHealth: making universal health coverage achievable. Report of the Third Global Survey on eHealth. Geneva: WHO; 2016.

21. IMS Institute for Healthcare Informatics. Patient adoption of mHealth. Use, evidence and remaining barriers to mainstream acceptance. Parsippany: IMS; 2015

22. Choi YK, Demiris G, Lin SY, Iribarre n SJ, Landis CA, Thompson HJ, et al. Smartphone applications to support sleep self-management: review and evaluation. J Clin Sleep Med. 2018 Oct;14(10):1783-90. DOI: https://doi.org/10.5664/jcsm.7396

23. Ong AA, Gillespie MB. Overview of smartphone applications for sleep analysis. World J Otorhinolaryngol Neck Surg. 2016 Mar;2(1):45-9. DOI: https://doi.org/10.1016/j.wjorl.2016.02.001

24. Fino E, Mazzetti M. Monitoring healthy and disturbed sleep through smartphone applications: a review of experimental evidence. Sleep Breath. 2018 Apr;23:13-24. DOI: https://doi.org/10.1007/s11325-018-1661-3

25. Camacho M, Robertson M, Abdullatif J, Certal V, Kram YA, Ruoff CM, et al. Smartphone apps for snoring. J Laryngol Otol. 2015 Sep;129(10):9749. DOI: https://doi.org/10.1017/S0022215115001978

26. Toon E, Davey MJ, Hollis SL, Nixon GM, Horne RSC, Biggs SN. Comparison of commercial wrist-based and smartphone accelerometers, actigraphy, and PSG in a clinical cohort of children and adolescents. J Clin Sleep Med. 2016 Mar;12(3):343-50. DOI: https://doi.org/10.5664/jcsm.5580

27. Bhat S, Ferraris A, Gupta D, Mozafarian M, DeBari VA, Gushway-Henry N, et al. Is there a clinical role for smartphone sleep apps? Comparison of sleep cycle detection by a smartphone application to polysomnography. J Clin Sleep Med. 2015 Jul;11(7):709-15. DOI: https://doi.org/10.5664/jcsm.4840

28. Natale V, Drejak M, Erbacci A, Tonetti L, Fabbri M, Martoni M. Monitoring sleep with a smartphone accelerometer. Sleep Biol Rhythms. 2012 Jul;10(4):287-92. DOI: https://doi.org/10.1111/j.1479-8425.2012.00575.x

29. Min JK, Doryab A, Wiese J, Amini S, Zimmerman J, Hong JI. Toss " $n$ " turn. New York: Association for Computing Machinery; 2014. DOI: https://doi.org/10.1145/2556288.2557220

30. Kolla BP, Mansukhani S, Mansukhani MP. Consumer sleep tracking devices: a review of mechanisms, validity and utility. Expert Rev Med Devices. 2016 Apr;13(5):497-506. DOI: https://doi.org/10.1586/17434440.2016.1171708

31. Ko PRT, Kientz JA, Choe EK, Kay M, Landis CA, Watson NF. Consumer sleep technologies: a review of the landscape. J Clin Sleep Med. 2015 Dec;11(12):1455-61. DOI: https://doi.org/10.5664/jcsm.5288 
32. Santo K, Richtering SS, Chalmers J, Thiagalingam A, Chow CK, Redfern J. Mobile phone apps to improve medication adherence: a systematic stepwise process to identify high-quality apps. JMIR mHealth uHealth. 2016 Oct/Dec;4(4):e132. DOI: https://doi.org/10.2196/mhealth.6742

33. Anderson K, Burford O, Emmerton L. App chronic disease checklist: protocol to evaluate mobile apps for chronic disease self-management. JMIR Res Protoc. 2016 Oct/Dec;5(4):e204. DOI: https://doi. org/10.2196/resprot.6194

34. Creber RM, Maurer MS, Reading M, Hiraldo G, Hickey KT, Iribarren S. Review and analysis of existing mobile phone apps to support heart failure symptom monitoring and self-care management using the Mobile Application Rating Scale (MARS). JMIR mHealth uHealth. 2016 Apr/ Jun;4(2):e74. DOI: https://doi.org/10.2196/mhealth.5882

35. Santoro E, Castelnuovo G, Zoppis I, Mauri G, Sicurello F. Social media and mobile applications in chronic disease prevention and management. Front Psychol. 2015;6:567. DOI: https://doi.org/10.3389/fpsyg.2015.00567

36. Singh K, Drouin K, Newmark LP, Rozenblum R, Lee J, Landman A, et al. Developing a framework for evaluating the patient engagement, quality, and safety of mobile health applications. Issue Brief (Commonw Fund). 2016 feb;5:1-11.

37. Scott H, Lack L, Lovato N. A pilot study of a novel smartphone application for the estimation of sleep onset. J Sleep Res. 2018 Jun;27(1):90-7. DOI: https://doi.org/10.1111/jsr.12575
38. Khosla S, Deak MC, Gault D, Goldstein CA, Hwang D, Kwon Y, et al Consumer sleep technology: an American Academy of Sleep Medicine position statement. J Clin Sleep Med. 2018 May;14(5):877-80. DOI https://doi.org/10.5664/jcsm.7128

39. Ho FYY, Chung KF, Yeung WF, Ng TH, Kwan KS, Young KP, et al. Self-help cognitive-behavioral therapy for insomnia: a meta-analysis of randomized controlled trials. Sleep Med Rev. 2015 Feb;19:17-28. DOI https://doi.org/10.1016/j.smrv.2014.06.010

40. Chung KF, Lee CT, Yeung WF, Chan MS, Chung EWY, Lin WL. Sleep hygiene education as a treatment of insomnia: a systematic review and meta-analysis. Fam Pract. 2018 Aug;35(4):365-75. DOI: https://doi.org/10.1093/fampra/cmx122

41. Stepanski EJ, Wyatt JK. Use of sleep hygiene in the treatment of insomnia. Sleep Med Rev. 2003 Jun;7(3):215-25. DOI: https://doi.org/10.1053/smrv.2001.0246

42. Al-Kandari S, Alsalem A, Al-Mutairi S, Al-Lumai D, Dawoud A, Moussa M. Association between sleep hygiene awareness and practice with sleep quality among Kuwait University students. Sleep Heal. 2017 Oct;3(5):3427. DOI: https://doi.org/10.1016/j.sleh.2017.06.004

43. Suen LKP, Tam WWS, Hon KL. Association of sleep hygiene-related factors and sleep quality among university students in Hong Kong. Hong Kong Med J. 2010 Jun;16(3):180-5.

44. Patel P, Kim JY, Brooks LJ. Accuracy of a smartphone application in estimating sleep in children. Sleep Breath. 2017;21:505-11. DOI: https:// doi.org/10.1007/s11325-016-1425-x 